\title{
Impact of Job Environment on Job Satisfaction \& Commitment among Nigerian Nurses
}

\author{
Osibanjo A.O, Abiodun A. J and Adeniji A. A \\ Covenant University, Ota, Nigeria
}

Correspondence should be addressed to: Osibanjo A.O; Osibanjo Adewale Omotayo

Received date: 24 September 2013; Accepted date: 2 January 2014; Published date: 28 November 2014

Copyright (C) 2014. Osibanjo A.O, Abiodun A. J and Adeniji A. A . Distributed under Creative Commons CC-BY 3.0

\begin{abstract}
The incessant strike, picketing among health workers in developing nations, is becoming a worrisome phenomenon in developing economy. This paper's main objective is to examine the impact of job environment (work-family interface, climate, work roles, and job security) on job satisfaction and commitment among Nigerian nurses. A model was developed and tested using two hundred and twenty eight valid questionnaires, which were completed by nurses in the public hospitals in Lagos, Nigeria. Structural Equation Modeling was adopted to test the hypotheses and relationships that might exist among variables. The results show that strong relationship exists between job security and job satisfaction; and workers are not satisfied with the present condition of the job environment. The summary of the findings indicates a good fit, which implies that there is strong correlation between the tested dependent and independent constructs. However, decision makers should endeavour to make job environment conducive in order to earn workers' commitment, which tends to increase organizational performance.
\end{abstract}

Keywords: Commitment, Job environment, Job satisfaction.

\section{Introduction}

Job dissatisfaction among workers has been a bone of contention and most researched variable among management and human resource researchers (Dhammika, Ahmad, \& Sam, 2001). The world is a global village, job seekers expect to be engaged in an organization that provides adequate work environment, free of environmental hazards, well ventilated, and secured thereby leading to job satisfaction. Essentially, researchers in the fields of organizational behaviour and management opined that the conceptual framework of the phenomena (satisfaction) is complex, indescribable and mythical (Malik, 2011). It has been argued that organizations cannot be at their best until workers are committed to the organizational goals and objectives (Dixit and Bhati, 2012). However, the degree to which workers are satisfied with their jobs varies and subjects to factors such as job environment, work hours and schedules, reward system, (Osibanjo, Abiodun, and Fadugba, 2012). In other words, workers' commitment can be described as a function of job satisfaction, which implies that workers could be 
committed in delivering their services when they are satisfied with their jobs and this may be influenced by job environment. Job environment includes workers' immediate vicinity where they carry out their assignments (Chapins, 1995); achieve management perceived and expected results (Shikdar, 2002, Mike, 2010). Job environment entails some basic features that tend to make workers satisfied with their jobs amongst which include; easy accessibility, ventilation, ergonomic furniture, cooling system, (Humphries, 2005; Veitch, Charles, Newsham, Marquardt \& Geerts, 2004); and these have positive impact on workers' health (Dilani, 2004; Milton, Glencross \& Walters, 2000). With the understanding that job formed an integral part of workers' life, it is therefore essential for workers to seek its satisfaction in order to be able to render their services without reservation, which tends to increase productivity at both employee and organizational levels. Job satisfaction as an independent variable can be influenced by other variables such as wages, benefits, job security, work type, family and so on.

\section{Need/Importance of the Study}

The survey became necessary because of the incessant conflicts among the health workers in the Nigerian public hospitals. In the recent past, health workers in Lagos State have being in and out of strikes/picketing due to the inability of the stakeholders in the health industry to harmonize and manage affairs effectively and efficiently. However, the resultant effects of these actions have caused irrecoverable damages such as death, deformities, etc. among the citizens. Having understood from the literature (reviewed above) that job environment is one of the major underlining factors that can make workers satisfied with their jobs. Therefore, this study is essential because it helps identify the challenges militating against health industry and subsequent proffer suggestions that will help alleviate these issues.

\section{Statement of the Problem}

The rate at which population is growing in Nigeria is very alarming, and it is obvious that the stakeholders in the health sector are negligent in the managing and utilization of the scarce resources (human and infrastructure). In the Nigerian health sector, workers' job satisfaction and commitment is linked with wages/salary and other benefits, whereby other factors such as job environment; work roles, job security, organizational climate \& work-family interface are not being addressed.

\section{Objectives}

The main objective for this research study is to examine the impact of job environment on workers' job satisfaction and commitment.

\section{Review of Literature}

\section{Job Environment and Job Satisfaction}

Job environment could be described as the physical, geographical, professional surroundings or conditions wherein employees interact with colleagues and equipment in order to carry out some specific activities. However, such professional surroundings could be either located at home or outside. Essentially, job environment is expected to be conducive, hazard free, well ventilation, etc. because hazardous environment tends to influence employees' performances (Bakotiæ and Babiæ, 2013). Choi, Cheung, and Pang (2012) identified five dimensions of job environment amongst which include coworker relationship, management, ward practice, etc. However, for the purpose of this study, we would like to specify the following variables to be tested under the job environment construct; organization climate, work roles, job security, and work-family interface. These variables shall be tested against job satisfaction and commitment among Nigerian nurses in the public hospitals. The term 'Job satisfaction' has been described by different authors; the state of 
emotion that relates with either positive or negative appraisal of work experiences (Locke, 1969); self-perception of fulfilling one's needs through work (Kreis and Brockopp, 1986); represents workers' evaluation of their work context (Thomas, Dose, and Scott, 2002); "state of mind determined by the extent to which the individual perceives his/her job related needs being met" (Freund, 2005). Further, job satisfaction is defined by Spector (1997) as "a global construct or as a constellation of different dimensions to which the employee reacts effectively". Put differently from a psychologist point of view, Dawes (2004) as cited in Muhammad, Samina, Basharat, and Rizwan (2010) opined that job satisfaction comprises of two components: (i) cognitive component; meaning workers having perception that their needs have being fulfilled, and (ii) affective component; the kind of feeling workers experience or have that comes with the perception. In a similar direction, as cited in Muhammad et al. (2010), McNamara (1999) described job satisfaction as feelings or state of mind of workers regarding the characteristics of their jobs. He went further to state that for workers to be satisfied with their jobs depends on variables such as work relationship with one's supervisor, the quality of physical work environment, oneself-actualization, among others. A critical analysis of the above definitions shows that job satisfaction connotes different meanings to different people, however, it could be deduced that job satisfaction is subjective and it depends on many factors (Weaver, 1980) such as one's feeling, state of mind, perception, frame of reference, work context, etc. As obtained in the literature, job satisfaction comprises of various elements such as remuneration, recognition, supervision, job security, and career advancement (Weiss, 2002). Further, physical job environment, quality of interpersonal relationship among workers; nature of the work (Ghazzawi, 2008; Judge and Church, 2000), tend to influence workers' job satisfaction; therefore we propose the following hypotheses:

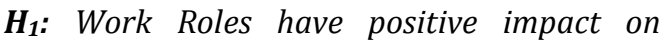
workers' job satisfaction;

$\boldsymbol{H}_{2}$ : Work Roles have positive impact on workers' commitment.

Job satisfaction could also be influenced by organizational climate, which could be described as the collective attitude of employees towards their organizations (Burton, Lauridsen, and Obel, 2004); experienced by workers, influences their behaviour and attitude (Tagiuri and Litwin, 1968). Organizational climate in comparison with organizational culture is regarded as a quantifiable concept and culture is seen as qualitative and less visible (Gould-Williams, 2007). Denison, (1996) argued that organizational climate is more concerned with 'those aspects of the social environment that are consciously perceived by organizational members'. Essentially, organizational climate can be seen as a combination of workers' useful perceptions that differentiate organizations in terms of procedure and practices. Therefore, we propose the following hypothesis:

$\boldsymbol{H}_{3}:$ There is positive impact of organizational climate on workers' job satisfaction and commitment.

Job security as obtained in the literature could be described as the feeling workers experience having assurance regarding the continuance of their jobs (Arabi, 2000); and avoidance of threats in the line of their jobs. Having job security implies that workers do not feel or perceive any kind of threat in the line of their duties; and as opined by Jandaghi, Mokhles, and Bahrami, (2011) organizational effectiveness is a function of employee commitment and satisfaction; similarly, Thomas (2006) described job security as one of the creators of job satisfaction and commitment. With these assertions, we propose: 


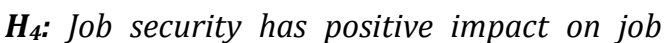
satisfaction among Nigerian Nurses.

$\boldsymbol{H}_{5}:$ Job security has positive impact on commitment among Nigerian Nurses.

Work can be described as an engagement of persons in physical or mental activity with the aim of achieving results, which often comes with financial gain. While family is described as a group, it comprises of parents and children living together in the same house. Work is essential and an important factor in sustaining and maintaining family in particular and society at large, and it is evident that work can generate stress as a result of interactions with colleagues and meeting set targets. However, there is a need to accept that work comes with its pros and cons, and therefore workers are expected to strike balance between work and family obligations. Work-family interface could be described as workers' continuous effort to maintain happiness and productive family and work lives. We therefore hypothesize that:

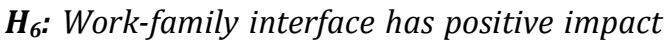
on job satisfaction among Nigerian Nurses.

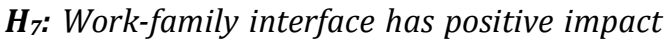
on commitment among Nigerian Nurses.

\section{Job Commitment and Job Satisfaction}

As obtained in the literature, organizational commitment as a variable related to sustained productivity (Dixit and Bhati, 2012); ethical climate types, facets of job satisfaction (Huang and Tsai, 2007); job satisfaction among teachers during times of burnout (Nagar, 2012); amongst others have been studied by researchers in the fields of organizational behaviour, psychology, and management. Organizational commitment is described as a three-component model viz-aviz Affective Commitment - degree to which employees believe and identify with the organization; Continuance Commitment employees' awareness of the cost of leaving their present organizations; and Normative Commitment is said to be the obligation employees have to remain with their present organizations (Meyer and Allen, 1991; Meyer, Stanley, Herscovitch, and Topolnytsky, 2002). As cited in Nagar (2012); Porter, Steers, Mowday, and Boulian (1974); and Cook and Wall (1980) conceptualized commitment as "the strength of an individual's identification with and involvement in a particular organization, characterized by a strong belief in an acceptance of an organization's goals and values; a willingness to exert considerable effort on behalf of the organization; and a definite desire to maintain organizational membership." Based on the above opinions, it is evident that commitment on the part of employees tends to provide results that are favourable to the organizations; and it can also predict employees' perceived behaviour (Dordevic, 2004).

\section{Hypotheses and Research Model}

This study will focus on the impact of job environment on job satisfaction and commitment among Nigerian Nurses. However, as obtained in the literature reviewed above, we propose the following research model depicted in fig 1. 


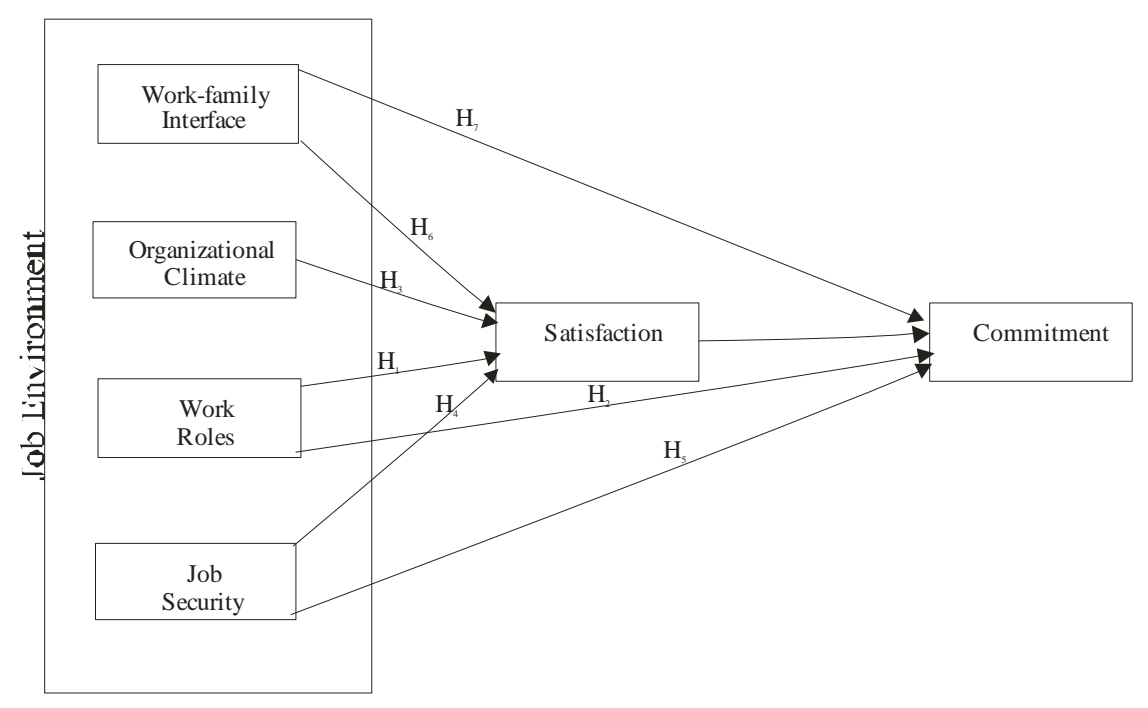

Figure 1: Proposed Study Model

\section{Research Methodology}

The empirical data for the study were collected through researchers' selfadministered questionnaires, which were prepared exclusively for nurses in four (4) public hospitals in Lagos, Southwest Nigeria. Methodological approach was adopted for the research design of this survey, which allows the use of primary data collected from the studied respondents on the impact of job environment on job satisfaction and commitment among Nigerian nurses. However, the choice of Nurses in the public health sector was based on the fact that Nigeria's health sector had been experiencing labour unrest. Convenience and purposeful sampling methods were utilized in order to derive the needed data for the study. Structured questionnaire was used to collect data and this was found appropriate because the views of the respondents were obtained. The research instrument is divided into two sections; the first tends to obtain the respondents' biodata; while the second part contains the items regarding the constructs of the subject matter; and this was based on a seven-point Likert scale (7 - Strongly agree; 6 - Agree; 5 - Moderately Agree; 4 Moderately Disagree; 3 - Disagree; 2 Strongly Disagree; and 1 - Not at all) that best describes the extent to which the respondents agree with each of the items in the questionnaire. The hypothesized proposed model in fig 1 was tested using Amos 21. A total of three hundred questionnaires were administered within the scope of the selected location, having sorted the returned questionnaires, the final valid sample size for the analysis was two hundred and twenty eight (228) which translate to a response rate of $76 \%$. The study tends to add to the existing literature on job environment and job satisfaction and commitment in developing economy such as Nigeria. 


\section{Results \& Discussion}

Respondents Demography

Table 1: Respondents demography

\begin{tabular}{|c|c|c|}
\hline & Frequency & Percentage \\
\hline \multicolumn{3}{|l|}{ Gender } \\
\hline Male & 22 & $9.6 \%$ \\
\hline Female & 206 & $90.4 \%$ \\
\hline Total: & 228 & $100.0 \%$ \\
\hline \multicolumn{3}{|l|}{$\overline{\text { Age }}$} \\
\hline $20-29$ years & 69 & $30.3 \%$ \\
\hline $30-39$ years & 69 & $30.3 \%$ \\
\hline $40-49$ years & 51 & $22.4 \%$ \\
\hline 50 years $\&$ above & 39 & $17.1 \%$ \\
\hline Total: & 228 & $100.0 \%$ \\
\hline \multicolumn{3}{|l|}{ Marital Status } \\
\hline Single & 81 & $35.5 \%$ \\
\hline Married & 116 & $50.9 \%$ \\
\hline Divorced & 31 & $13.6 \%$ \\
\hline Total: & 228 & $100.0 \%$ \\
\hline \multicolumn{3}{|l|}{ Years of Experience } \\
\hline $0-9$ years & 55 & $24.1 \%$ \\
\hline $10-19$ years & 114 & $50.0 \%$ \\
\hline 20 years \& above & 59 & $25.9 \%$ \\
\hline Total: & 228 & $100.0 \%$ \\
\hline \multicolumn{3}{|l|}{ Department } \\
\hline Critical Care & 38 & $16.7 \%$ \\
\hline Surgery & 54 & $23.7 \%$ \\
\hline Internal medicine & 53 & $23.2 \%$ \\
\hline Outpatient & 43 & $18.9 \%$ \\
\hline Emergency Room & 40 & $17.5 \%$ \\
\hline Total: & 228 & $100.0 \%$ \\
\hline
\end{tabular}

\section{Source: Survey, 2013}

It is evident in Table 1 that $9.6 \%$ of the sample size were males while $90.4 \%$ were females, which implies that the female population is higher than the male counterpart in the nursing profession. This makes this survey appropriate and valid because much is expected from the female gender regarding family obligations. Further, about $60.5 \%$ (cumulative percentage) of the respondents were within the active age range. Also, half of the respondents (50.9\%) were married; while $35.5 \%$ were unmarried; and $13.6 \%$ divorced, though the reasons for their present marital status could not be ascertained at the time of documenting this report. Regarding the years of work experience, $50.0 \%$ of the respondent had worked between 10 and 19 years, while $25.9 \%$ has put in 20 years and about, which makes the respondents authority in responding to the questionnaire. 


\section{Discussion}

Hooper, Coughlan, and Mullen (2008) described Structural Equation Modelling (SEM) as a technique being adopted by researchers across disciplines to test their variables and identify whether the model fits and represents the underlying proposed theory. Similarly, we adopted Amos 21 for the analysis of data obtained from this survey. The goodness of fit of a model explains the extent to which it fits the observed and expected values. Further, as cited in Adeniji, Osibanjo; and Abiodun (2013), the works of Bentler and Wu, 2002; Kaplan, 2000; and Hair, Anderson, Tathan, \& Black (1998) argue that various goodness-offit indicators are used to evaluate research models. A model is acceptable if the NormedFit Index (NFI) exceeds 0.90 indicating a good fit, and the Comparative Fit Index (CFI) the statistical values range between 0.0 and 1.0 with values closer to 1.0 representing good fit (Hooper et al, 2008). As shown in Table 2 (the survey Model Fit summary); the Normed Fit Index (NFI) value for this model is .999 , which indicates that the model of interest improves the fit by $99.9 \%$ relative to the independence model; while the Comparative Fit Index (CFI) value equals 1.000 indicating a goof fit, thereby making the model acceptable. As cited in Hooper et al (2008), The Root Mean Square Error of Approximation (RMSEA) that is referred to as the second fit statistic says how well the model, and it was obtained that an RMSEA value below 0.08 shows a good fit (MacCallum, Browne, and Sugawara, 1996), therefore the RMSEA value obtained from this analysis is .000 which makes it a perfect and acceptable fit.

\section{Table 2: Model Fit Summary}

\begin{tabular}{|c|c|c|}
\hline Model Fix index & Score & Recommended cut-off value \\
\hline Chi-square/Degree of Freedom & .330 & \\
\hline Comparative Fix Index (CFI) & 1.000 & $\begin{array}{l}\text { Values greater than } 0.9 \text { (Bentler and Bonnet, } \\
\text { 1980) }\end{array}$ \\
\hline Normed Fit Index (NFI) & .999 & Values greater than 0.9 \\
\hline $\begin{array}{lccc}\text { Root Mean Square } & \text { Error } & \text { of } \\
\text { Approximation (RMSEA) } & & \\
\end{array}$ & .000 & $\begin{array}{l}\text { Values lower than } 0.08 \text { (MacCallum, Browne, } \\
\text { and Sugawara, 1996) }\end{array}$ \\
\hline CMIN & .330 & \\
\hline Degrees of Freedom (DF) & 1 & \\
\hline Probability Level & .566 & \\
\hline
\end{tabular}

Source: Survey, 2013

\section{Hypotheses Testing Results}

The results of the path analysis, presented in Table 3, show that Job satisfaction appears to be positively influenced by variables such as: Work roles $\left(\mathrm{H}_{1}\right)$; Organizational climate $\left(\mathrm{H}_{3}\right)$; Job security $\left(\mathrm{H}_{5}\right)$; and Work-family interface $\left(\mathrm{H}_{7}\right)$. Evidently, organizational climate and job security tend to be more significant than other variables tested against job satisfaction. By implication, organizational climate and job security are observed to be great determinants of workers' satisfaction in rendering their services. While on the other hand, workers' commitment appeared to be positively influenced by work roles $\left(\mathrm{H}_{2}\right)$; Job security $\left(\mathrm{H}_{5}\right)$; and Work-family interface

$\left(\mathrm{H}_{7}\right)$. 
Table 3: Hypotheses Testing Results

\begin{tabular}{|l|c|c|}
\hline \multicolumn{1}{|c|}{ Hypotheses } & Path Coefficient & Remark \\
\hline Work role (W roles) $\rightarrow$ Satisfaction & .08 & Accepted \\
\hline Work role (W roles) $\rightarrow$ Commitment & .33 & Accepted \\
\hline Climate $\rightarrow$ Satisfaction & .34 & Accepted \\
\hline Security $\rightarrow$ Satisfaction & .32 & Accepted \\
\hline Security $\rightarrow$ Commitment & .23 & Accepted \\
\hline Work-family interface $\rightarrow$ Satisfaction & -.04 & Accepted \\
\hline Work-family interface $\rightarrow$ Commitment & -.01 & Accepted \\
\hline
\end{tabular}

Note: All path coefficients are significant at the $\mathrm{p}<0.001$

Source: Survey, 2013

The results of Model Fit for Job Environment and Job Satisfaction and Commitment are depicted in Fig 2. It is evident that close association exists among the variables observed under job environment construct. The path coefficient between job security and organizational climate is .42 , which indicates positive and significant correlation; similarly, work roles and organizational climate (.50) also displays high correlation; also job security and work roles with coefficient value of .40 .



Figure 2: Results of Model Fit for Job Environment and Job Satisfaction and Commitment

\section{Findings}

The survey examined the impact of job environment on job satisfaction and commitment among Nigerian nurses; and the study was limited to Lagos Southwest Nigeria. All the relationships proposed among the variables in the research model were tested and it was found that strong association exists amongst the variables, having subjected the collected data to empirical analysis with the use of structural equation modeling. However, the results of the findings indicated that nurses are less satisfied with the current job environment, which implies that nurses can be more satisfied if there is improvement in job environment with particular emphasis on the variables (family-life interface, climate, work roles, and security) studied. The overall 
analysis showed that proposed hypotheses tested are accepted and the goodness of fit indexes showed a good fit. It is therefore evident that job satisfaction and commitment among nurses in Nigeria can be boosted by providing an environment that is conducive, adequately secured, and ensure that there is balance between work and family, also the task be performed should not be above workers' capacities. It could be suggested that for nurses in Nigeria and developing nations to be satisfied and committed to their jobs, there is a need for the decision makers to provide a better job environment in order to have committed and satisfied workforce, which tends to increase organizational performance and also save lives and costs.

\section{Scope for Further Research}

This survey was self-administered and selfsponsored, and was conducted at the general hospitals in Lagos, Southwest Nigeria. This reduces the possibility of generalizing and implementing the findings in other parts of Nigeria, which implies that the findings should be interpreted with caution taking the diversity that exists in Nigeria into consideration. Nigeria comprises of sixgeopolitical zones, it is therefore suggested that such research should be sponsored and replicated in these geopolitical zones for stakeholders and decision makers in the Nigerian health sector to be able to make adequate recommendations and implement these suggestions thereof.

\section{Acknowledgement}

We would like to appreciate the Management and Colleagues in the Department of Business Management, and graduating class (2012/2013), Covenant University for their support in administering the questionnaires and collating them.

\section{References}

1. Adeniji, A. A., Osibanjo A. O., \& Abiodun

A. J. (2013) 'Organizational Change and
Human Resource Management Interventions: An Investigation of the Nigerian Banking Industry,' Serbian Journal of Management. 8 (2).

2. Arabi S. M. (2000) Strategies, plans and guidelines to achieve job security. Management Studies Q., p. 37.

3. Bakotiæ, D. and Babiæ, T. (2013) 'Relationship between Working Conditions and Job Satisfaction: The Case of Croatian Shipbuilding Company,' International Journal of Business and Social Science Vol. 4 (2).

4. Bentler, P. M. and Bonett, D. C., (1980). "Significance Tests and Goodness of Fit in the Analysis of Covariance Structures," Psychological Bulletin. Vol. 88 (3).

5. Bentler, P.M., \& Wu, E.J.C. (2002). EQS 6 for windows user's guide. Encino: Mulitvariate Software.

6. Burton, R.M., Lauridsen, J. and Obel, B. (2004) 'The Impact of Organizational Climate and Strategic Fit on Firm Performance', Human Resource Management. Vol. 43(1): 67-82.

7. Chapins, A. (1995). Workplace and the performance of workers. Reston: USA.

8. Choi, S. P., Cheung, K., and Pang, S. M. (2012). Attributes of nursing work environment as predictors of registered nurses' job satisfaction and intention to leave. Journal of Nursing Management. Vol. 21 (3).

9. Cook, J. \& Wall, T. (1980). New work attitude measures of trust, organisational commitment and personal need nonfulfilment. Journal of Occupational Psychology. Vol. 53, 39-52.

10. Dawes, R. V. (2004). Job satisfaction. In M. Hersen \& J.C. Thomas (Eds.) Comprehensive handbook of Psychological 
assessment: Vol. 4, 470-481. Hoboken, N.J.: John Wiley \& Sons.

11. Denison, D.R. (1996) 'What is the Difference Between Organizational Culture and Organizational Climate? A Native's Point of View on a Decade of Paradigm Wars', Academy of Management Review, 21(3): 61954.

12. Dhammika, K.A.S., Ahmad, F.B., and Sam, T. L. (2001), "Job Satisfaction, Commitment and Performance: Testing the Goodness of Measures of Three Employee Outcomes," South Asian Journal of Management. Vol. 19 (2)

13. Dilani, A. (2004). Design and health III: Health promotion through environmental design. Stockholm, Sweden: International Academy for Design and Health.

14. Dixit, V., and Bhati, M. (2012). A Study about Employee Commitment and its impact on Sustained Productivity in Indian AutoComponent Industry. European Journal of Business and Social Sciences, Vol. 1(6), pp 34 51.

15. Dordevic, B. (2004). Employee Commitment in Times of Radical Organisational Changes. Economics and Organisation. Vol. 2 (2).

16. Freund, A. (2005). Commitment and job satisfaction as predictors' turnover intentions among welfare workers. Administration in Social Work, 29(2), 5-21.

17. Gould-Williams, J. (2007). HR practices, organizational climate and employee outcomes: evaluating social exchange relationships in local government. International Journal of Human Resource Management. Vol. 18 (9) 1627 - 1647

18. Hair, J. F., Anderson, R. E., Tatham, R. L., \& Black, W. C. (1998). Multivariate Data Analysis, 5th. New Jersey: Prentice-Hall Inc.
19. Hooper, D., Coughlan, J., and Mullen, M. R. (2008). Structural Equation Modelling: Guidelines for Determining Model Fit. The Electronic Journal of Business Research Methods. Vol. 6 (1).

20. Huang, C., and Tsai, M. (2008). The Relationship among Ethical Climate Types, Facets of Job Satisfaction, and the Three Components of Organizational Commitment: A Study of Nurses in Taiwan. Journal of Business Ethics. Vol. 80:565-581

21. Humphries, M. (2005). Quantifying occupant comfort: Are combined indices of the indoor environment practicable? Building Research and Information. Vol. 33(4), 317325.

22. Jandaghi, G., Mokhles, A., and Bahrami, H. (2011). The impact of job security on employees' commitment and job satisfaction in Qom municipalities. African Journal of Business Management Vol.5 (16), pp. 68536858.

23. Kaplan, D. (2000). Structural equation modeling: Foundations and extensions. Thousand Oaks: Sage Publications.

24. Kreis, K., \& Brockopp, D.Y. (1986). Autonomy: A component of teacher job satisfaction.

25. Locke, E.A. (1969). What is Job Satisfaction? Organizational Behavior and Human, 4, 309-336.

26. MacCallum, R. C., Browne, M. W., and Sugawara, H. M. (1996). "Power Analysis and Determination of Sample Size for Covariance Structure Modelling," Psychological Methods. Vol. 1 (2).

27. Malik. N. (2011). Study on job satisfaction factors of faculty members at university of Balochistan. International Journal of Academic research, 3(1), 2011, Part I 
28. McNamara. (1999). Job satisfaction. Retrieved December 6, 2006, [Online] Available:

http://www.managementhelp.org/prsn_wll/ job_stfy.htm.

29. Meyer, J. P. \& Allen, N.J. (1991). A threecomponent conceptualization of organisational commitment. Human Resource Management Review. Vol. 1(1), 61-89.

30. Meyer, J. P., Stanley, D.J., Herscovitch, L. \& Topolnytsky, L. (2002). Affective, continuance and normative commitment to the organisation: A meta-analysis of antecedents, correlates and consequences. Journal of Vocational Behaviour. Vol. 61(1), 20-52.

31. Mike, A. (2010). Visual workplace: How you see performance in the planet and in the office. International Journal of Financial Trade. Vol. 11(3), 250-260.

32. Milton, D.K., Glencross, P.M. \& Walters, M.D. (2000). Risk of sick leave associated with outdoor air supply rate, humidification and occupant complaints. Indoor Air. Vol. $10(4), 212-221$.

33. Muhammad, E. M., Samina, N., Basharat, N., and Rizwan, Q. D. (2010). Job Satisfaction and Organizational Commitment of University Teachers in Public Sector of Pakistan. International Journal of Business and Management. Vol. 5 (6)

34. Nagar, K. (2012). Organizational Commitment and Job Satisfaction among Teachers during Times of Burnout. VIKALPA. Vol. 37(2)

35. Osibanjo, A. O., Abiodun, A. J., and Fadugba, A. O. (2012) Executives Perception of the Impact of Flexitime on Organizational Performance: Evidence from the Nigerian Private Sector. : International Journal of Applied Behavioral Economics (IJABE). Vol. 1 (3)
36. Porter, L.W., Steers, R.M., Mowday, R.T. \& Boulian, P.V. (1974). Organizational commitment, job satisfaction and turnover among psychiatric technicians. Journal of Applied Psychology, 59(5), 603-609.

37. Shikdar, A.A. (2002). Identification of ergonomic issues that affect workers in oilrigs in desert environment. International Journal of Occupational Safety and Ergonomic. Vol. 10(8), 169-177.

38. Spector, P. (1997). Job satisfaction. Thousand Oaks, CA: Sage.

39. Tagiuri, R. and Litwin, G.H. (1968) 'Organizational Culture: A Key to Financial Performance'. In Schneider, B. (ed.) Organizational Climate and Culture. San Francisco, CA: Jossey-Bass.

40. Thomas, P., Dose, J., \& Scott, K. (2002). Relationships between accountability, job satisfaction, and trust. Human Resource Development Quarterly, 13, 307-323.

41. Veitch, J. A., Charles, K.E., Newsham, G.R., Marquardt, C.J.G., \& Geerts, J. (2004). Workstation characteristics and environmental satisfaction in open-plan offices. COPE Field Findings (NRCC-47629) Ottawa, Canada: National Research Council.

42. Weaver C. N. (1980). Job satisfaction in the United States in the 1970s. Journal of Applied Psychology, 65 (3), 364-367.

43. Weiss H. M. (2002). Deconstructing job satisfaction: separating evaluations, beliefs and affective experiences. Human Resource Management Review, 12, 173-194. 